\title{
Genera of Spore-Feeding Thysanoptera from Southeast Asia (Phlaeothripidae, Idolothripinae), with a species checklist from Peninsular Malaysia
}

\author{
L.X. EOW ${ }^{1}$, L.A. MOUND ${ }^{2} \&$ Y.F. NG $^{1}$ \\ ${ }^{1}$ Centre for Insect Systematics (CIS), Universiti Kebangsaan Malaysia, 43600 Bangi, Selangor, Malaysia. \\ E-mail:elx163@yahoo.co.uk;ng_yf@ukm.my \\ ${ }^{2}$ CSIRO Ecosystem Sciences, Canberra, ACT 2601, Australia.E-mail: laurence.mound@csiro.au
}

\begin{abstract}
An illustrated key is provided to the 31 genera of the subfamily Idolothripinae recorded from Southeast Asia, and a checklist provided to 34 species recorded from Peninsular Malaysia. Notes are given on the habitat preferences of these fungal spore-feeding thrips, together with for each genus some discussion of systematic relationships and species diversity.
\end{abstract}

Key words: Thysanoptera, Phlaeothripidae, Idolothripinae, Southeast Asia, Malaysia, spore-feeding

\section{Introduction}

Adults and larvae of the Thysanoptera subfamily Idolothripinae often exist as large colonies on dead leaves and dead branches, where they are considered to feed on fungal spores (Tree et al., 2010). Members of this subfamily, Idolothripinae, exhibit a wide range of body form, and the body size ranges from about $1 \mathrm{~mm}$ to over $15 \mathrm{~mm}$ (Figs. 37-45). Many species in this group of thrips are particularly interesting biologically. Sexual dimorphism can be so extreme that conspecific males and females have sometimes been allocated mistakenly to different species, or even different genera. Even more impressive is the polymorphism found among the males of many species, with allometry of several body structures in association with great variation in body size. In Southeast Asia the significance of such male polymorphism remains unstudied, but in other parts of the world intraspecific variation among male thrips has been found to be associated with male/male competition and combat (Crespi, 1989; Mound, 2005). Moreover, some of these species exhibit varying rates of sex allocation and of reproductive mode, such as viviparity and ovoviviparity (Kranz et al., 2002). Ecologically, the close relationship of these thrips with the microfungi on wood and plant debris, as well as their role in the tropical forest, is not well explored. The Idolothripinae thus constitute a group of readily available insects in tropical Asia that are well suited for interesting biological as well as ecological studies. Moreover, rearing methods have been developed that can be used to produce laboratory cultures for suitable experimentation (Shibata et al., 2007).

Thrips, insects of the Order Thysanoptera, are commonly thought of as pests of flowers and leaves, and studies on their biology are commonly left to economic entomologists. However, about 50\% of the known 5500 species feed only on fungus (Morse \& Hoddle, 2006), many on hyphae but with members of the Phlaeothripidae subfamily Idolothripinae feeding on fungal spores. Unfortunately, there is a serious lack of taxonomic revisionary studies for thrips from Southeast Asia. Thrips are so little known in Malaysia that they have no local name. When shown these insects during field trips, locals commonly referred to those found on flowers as 'flower lice' and those found on wood as 'wood lice' or sometimes 'small scorpions'. This is not too curious as it is natural that local people should refer to any minute arthropods on plants or wood as 'lice'. In a bigger picture, the Thysanoptera fauna of Southeast Asia is highly diverse, but with large areas effectively un-sampled. These include Myanmar, Laos, Vietnam and Cambodia. The thrips identification systems that are most readily available in tropical countries (Mound \& Kibby, 1998; Moritz et al., 2004) give little indication of the wide structural and biological diversity within this Order of insects, while the more specialist literature is widely scattered through many publications, for example, for Thai- 
land (Nonaka \& Jangvitaya, 1994; Okajima, 1993, 1998, 2002). The other comprehensive texts relevant to the Idolothripinae are introductions to the Thysanoptera of the Philippines (Reyes, 1994), and to the Phlaeothripidae of Japan (Okajima, 2006), together with a checklist of the Thysanoptera recorded from Indonesia (zur Strassen, 1994). An introduction to the thrips fauna of India (Ananthakrishnan \& Sen, 1980) is now seriously out of date, due to many nomenclatural and systematic changes in subsequent years. Palmer and Mound (1978) published on nine genera of Oriental fungus feeding thrips, while Mound and Palmer (1983) provided an introduction to the Idolothripinae genera of the world — both continue to be useful references, but some keys to species (Palmer \& Mound, 1978) are now considered to be an unsatisfactory assessment of variation, and the key to world genera of Idolothripinae (Mound \& Palmer, 1983) has proven difficult when used for the Asian local fauna. One measure towards alleviating this problem is the progressive development of profusely illustrated, web-based information and identification systems (Mound, 2011; Mound et al. 2011 ), and also gradual establishment of local collections, as well as collaboration between the Southeast Asian institutions, as discussed in Mound \& Ng (2009). In contrast, the present paper is the fourth in a series targeting the local thrips fauna of Peninsular Malaysia (Mound \& Azidah, 2009; Mound \& Ng, 2009; Ng et al., 2010), based particularly on recent field studies between the years 2009-2010. Despite focussing on the fauna of Malaysia, the authors hope that the illustrated identification system to this specific group of thrips will provide a foundation for future biological studies on the diverse thrips fauna in the wider Asian tropics.

As indicated throughout the text, the Thysanoptera fauna of Southeast Asia remains poorly known, and there is much to be discovered. The objective of the work presented here is to provide a relatively simple illustrated key to, and overview of, the genera of Idolothripinae that are known from Southeast Asia, between Myanmar in the West and New Guinea in the East. Because of the great variation within some species, in terms of body structure, colour and size, it is essential to collect large samples of a population, and to mount onto microscope slides (Hoddle et al., 2008) a series of undistorted specimens. Too much pressure applied onto a cover slip when mounting a specimen alters the shape of head, maxillary stylets, and other body parts of the flattened-out thrips, especially when most of the Idolothripinae are large, thick species. Attempts to identify isolated single individuals often lead to errors.

Habitats of Idolothripinae. In Southeast Asia, large dark species such as those of the genus Elaphrothrips are particularly associated with dead hanging leaves. Some individuals will, at times, be found on dead twigs and even on dead leaves on the ground, but substantial colonies are usually found on those dead leaves that are hanging in bunches where they are exposed to sunlight and there is good air circulation. This habitat is shared with the species of Mecynothrips, Bactrothrips and Meiothrips. In contrast, the equally large species of the genus Dinothrips and Machatothrips form large colonies on fallen tree trunks or dead branches, and are less frequently taken from hanging dead leaves. Recently dead branches and dead twigs also provide the habitat for a wide range of spore-feeding species, for example members of the genera Acallurothrips, Diaphorothrips, Ethirothrips, Gastrothrips and Nesothrips. A very different habitat, leaf-litter that is often rather moist, seems to be favoured by species of Holurothrips, whereas Allothrips species are probably associated with rather well-drained leaf-litter. Also at ground level, but specifically at the base of tussocks of grass, is another suite of thrips, including the genera Compsothrips and Ophthalmothrips, as well as some species of Carientothrips. For most of these thrips species, the species of fungus used as food remains unknown, thus any specificity remains to be determined. However, it is evident from slidemounted specimens that there is a broad correlation between the width of the maxillary stylets and the size of ingested spores.

Classification of Idolothripinae. The Idolothripinae is the smaller of the two subfamilies in the Phlaeothripidae. It comprises about 700 species worldwide, whereas the Phlaeothripinae comprises 2800 species. The classification adopted here follows that of Mound \& Palmer (1983) in recognising two Tribes within the Idolothripinae, the Pygothripini with six subtribes, and the Idolothripini with three subtribes. All nine of these major groups are represented in the fauna of Southeast Asia (Table 1), but individual species within each of the groups often exhibit one or more characters in a state not shared with species that are considered closely related. As a result, clear-cut definition of each of the subtribes and many genera of these polymorphic insects is not possible. Full nomenclatural details of all taxa discussed here are available at the website: http://www.ento.csiro.au/thysanoptera/ worldthrips.html. 
TABLE 1. List of Idolothripinae genera recorded from Southeast Asia.

[Family-group classification after Mound \& Palmer, 1983]

\section{SUBFAMILY IDOLOTHRIPINAE}

\section{TRIBE IDOLOTHRIPINI Bagnall}

SUBTRIBE IDOLOTHRIPINA Bagnall

Bactrothrips Karny

Megalothrips Uzel

Meiothrips Priesner

SUBTRIBE ELAPHROTHRIPINA Mound \& Palmer

Dinothrips Bagnall

Elaphrothrips Buffa

Malesiathrips Palmer \& Mound

Mecynothrips Bagnall

Ophthalmothrips Hood

SUBTRIBE HYSTRICOTHRIPINA Karny

Holurothrips Bagnall

Neatractothrips Mound \& Palmer

Paractinothrips Mound \& Palmer

\section{TRIBE PYGOTHRIPINI Hood}

\section{SUBTRIBE PYGOTHRIPINA Hood}

Phaulothrips Hood

Pygothrips Hood

SUBTRIBE ALLOTHRIPINA Priesner

Allothrips Hood

Anallothrips Okajima \& Urushihara

SUBTRIBE COMPSOTHRIPINA Karny

Compsothrips Reuter

SUBTRIBE GASTROTHRIPINA Priesner

Gastrothrips Hood

SUBTRIBE DICERATOTHRIPINA Karny

Acallurothrips Bagnall

Carientothrips Moulton

Neosmerinthothrips Schmutz

Nesothrips Kirkaldy

SUBTRIBE MACROTHRIPINA Karny

Aesthesiothrips Ananthakrishnan

Celidothrips Priesner

Diaphorothrips Karny

Dichaetothrips Hood

Ethirothrips Karny

Machatothrips Bagnall

Macrothrips Bagnall

Peltariothrips Mound \& Palmer

Polytrichothrips Priesner

Tarassothrips Mound \& Palmer 
TABLE 2. Idolothripinae recorded from States in Peninsular Malaysia, and Singapore. [Based on sampling in 2009-2010 and published records in Mound (1974), Palmer \& Mound (1978), and Mound \& Palmer (1983)]

\begin{tabular}{|c|c|}
\hline Taxa & Locality \\
\hline Acallurothrips metulicauda Karny & Selangor. \\
\hline Bactrothrips idolomorphus Karny & Negeri Sembilan, Pahang. \\
\hline Diaphorothrips clavipes Priesner & Selangor, Singapore. \\
\hline Diaphorothrips hamipes Karny & Pahang, Selangor. \\
\hline Dichaetothrips okajimai Mound \& Palmer & Pahang, Singapore. \\
\hline Dinothrips spinosus Schmutz & Johor, Pahang, Perak, Selangor, Kuala Terengganu, Singapore. \\
\hline Dinothrips sumatrensis Bagnall & Pahang, Selangor, Johor, Perak, Kuala Terengganu. \\
\hline Elaphrothrips bakeri Karny & Kedah, Pahang, Selangor, Negeri Sembilan. \\
\hline Elaphrothrips curvipes Priesner & Selangor, Negeri Sembilan, Kedah, Pahang, Penang. \\
\hline Elaphrothrips denticollis Bagnall & Selangor, Negeri Sembilan, Kedah, Pahang. \\
\hline Elaphrothrips jacobsoni Priesner & Pahang, Selangor. \\
\hline Elaphrothrips malayensis Bagnall & Johor, Kedah, Negeri Sembilan, Pahang, Selangor. \\
\hline Elaphrothrips procer Schmutz & Selangor. \\
\hline Ethirothrips stenomelas Walker & Pahang, Selangor. \\
\hline Ethirothrips tibialis Okajima & Pahang, Selangor. \\
\hline Gastrothrips acuticornis Hood & Selangor. \\
\hline Gastrothrips acutulus Okajima & Pahang. \\
\hline Holurothrips ornatus Bagnall & Kedah, Johor. \\
\hline Machatothrips antennatus Bagnall & Johor, Pahang, Selangor, Singapore. \\
\hline Machatothrips biuncinatus Bagnall & Pahang, Selangor, Singapore. \\
\hline Machatothrips decorus Palmer \& Mound & Pahang, Selangor. \\
\hline Machatothrips heveae Karny & Pahang, Selangor. \\
\hline Machatothrips lentus Palmer \& Mound & Johor, Pahang, Selangor, Singapore. \\
\hline Malesiathrips malayensis Palmer \& Mound & Selangor. \\
\hline Mecynothrips simplex Bagnall & Johor, Kedah, Pahang, Penang. \\
\hline Meiothrips annulipes Bagnall & Kedah, Pahang, Perak, Selangor, Negeri Sembilan. \\
\hline Meiothrips menoni Ananthakrishnan & Pahang, Perak, Selangor. \\
\hline Megalothrips andrei Mound \& Palmer & Selangor. \\
\hline Nesothrips brevicollis Bagnall & Melaka. \\
\hline Nesothrips lativentris Karny & Selangor, Pahang. \\
\hline Nesothrips malaccae Mound & Selangor. \\
\hline Peltariothrips insolitus Mound \& Palmer & Singapore. \\
\hline Paractinothrips peratus Mound \& Palmer & Selangor. \\
\hline Tarassothrips akritus Mound \& Palmer & Selangor, Singapore. \\
\hline
\end{tabular}



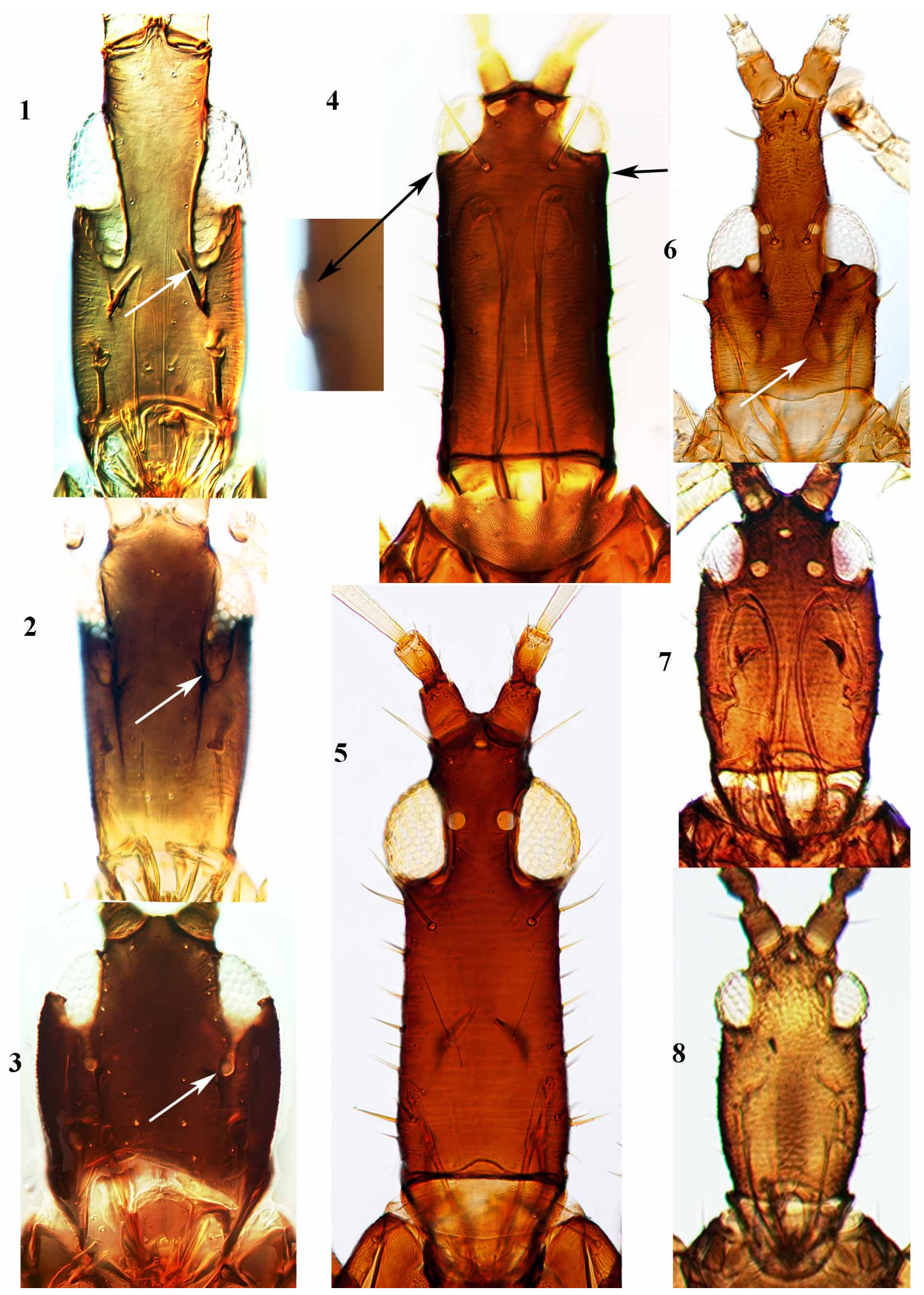

FIGURES 1-8. Idolothripinae heads. Ventral, (1-3): (1) Ophthalmothrips, (2) Compsothrips, (3) Carientothrips. Dorsal, 4-8: (4) Celidothrips, (5) Elaphrothrips, (6) Holurothrips, (7) Tarassothrips, (8) Malesiathrips. 

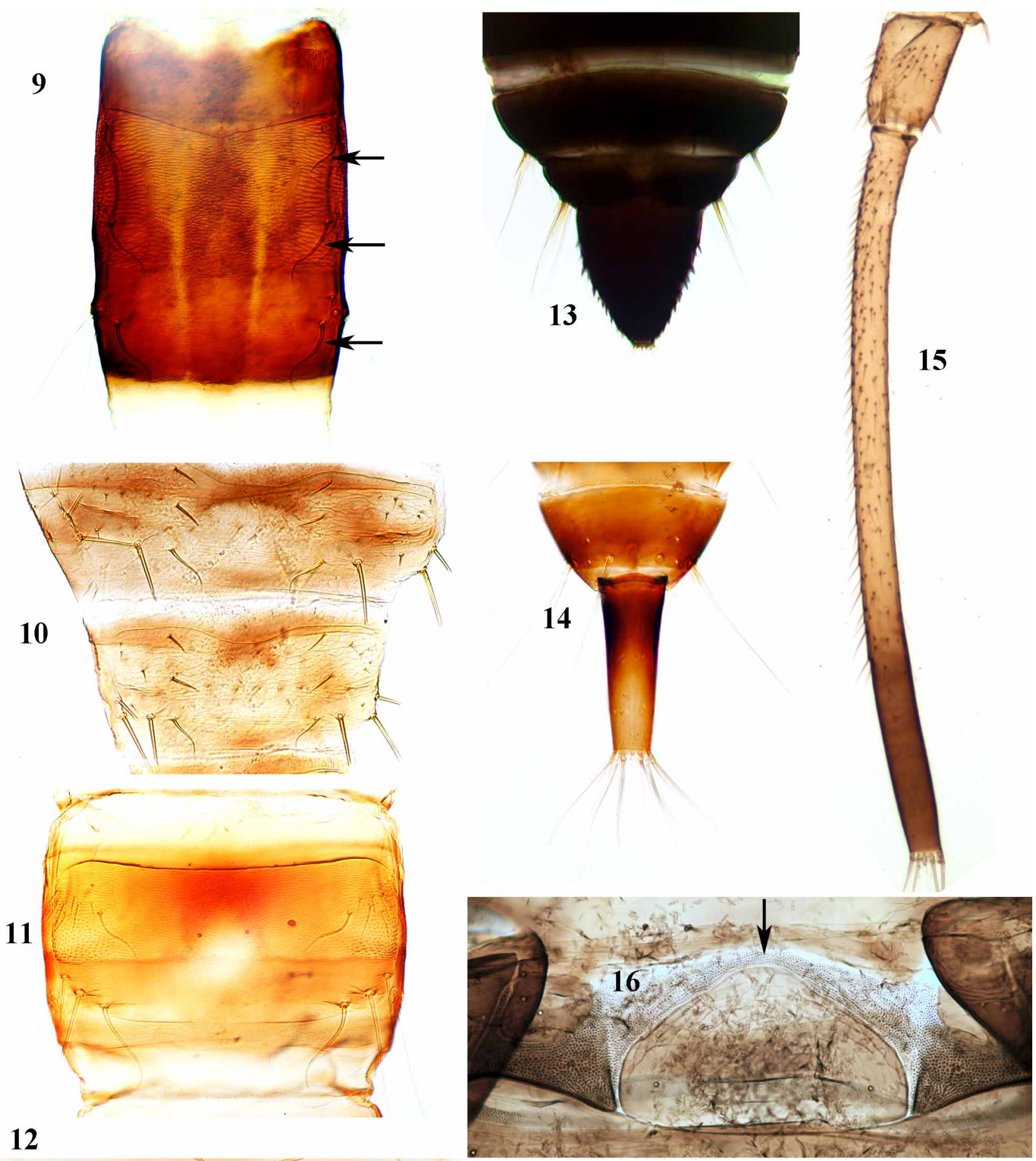

12
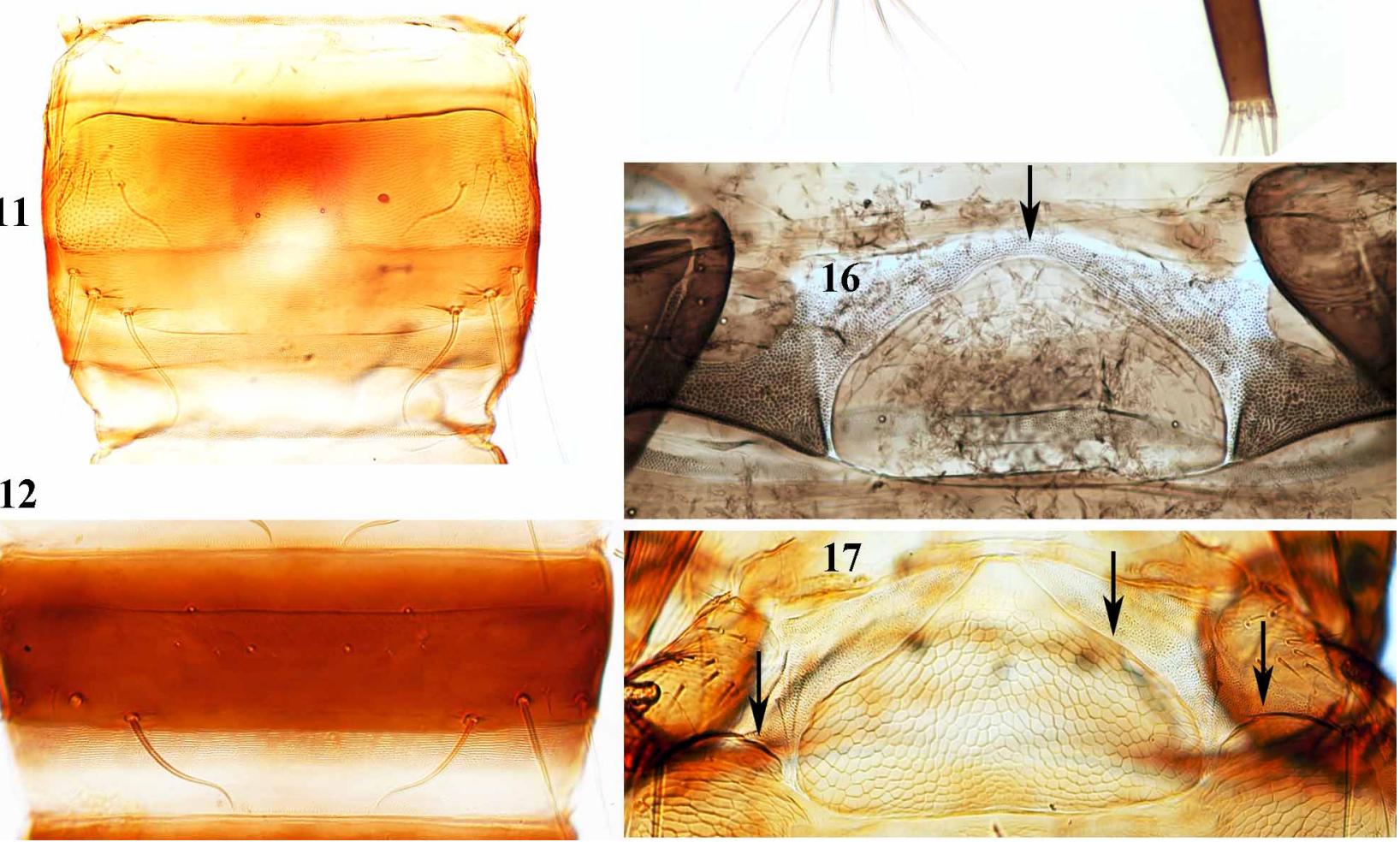

FIGURES 9-17. Idolothripinae species, structural details. Tergal wing retaining setae, 9-12: (9) Mecynothrips, (10) Holurothrips, (11) Dinothrips, (12) Gastrothrips. Abdominal segment X (tube), 13-15: (13) Acallurothrips, (14) Gastrothrips, (15) Holurothrips. Pelta, 16-17: (16) Dichaetothrips, (17) Dinothrips. 


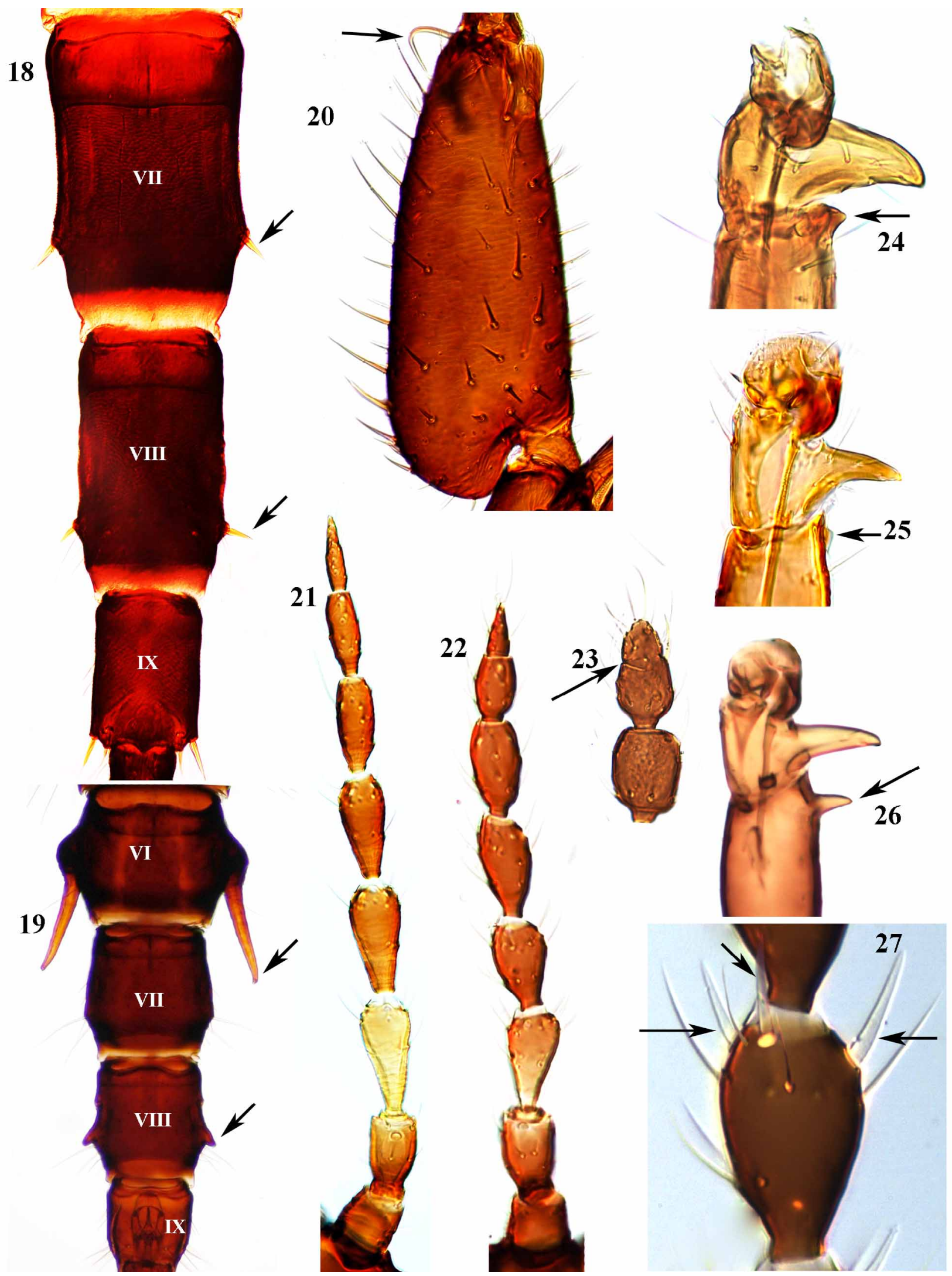

FIGURES 18-27. Idolothripinae species, structural details. (18) Male tergites VII-IX, Meiothrips. (19) Male tergites VI-IX, Bactrothrips. (20) Male fore femur, Elaphrothrips. Antennal segments I-VIII, 21-22: (21) Diaphorothrips hamipes, (22) Gastrothrips acutulus. (23) Antennal segment VI-VIII with incomplete suture between VII-VIII, Anallothrips. Fore tibia apical tubercle, 24-25: (24) male Machathothrips antennatus, (25) Ethirothrips tibialis. (26) Fore tibia sub-apical tubercle, Diaphorothrips hamipes. (27) Antennal segment IV with three sensoria, Gastrothrips acutulus. 


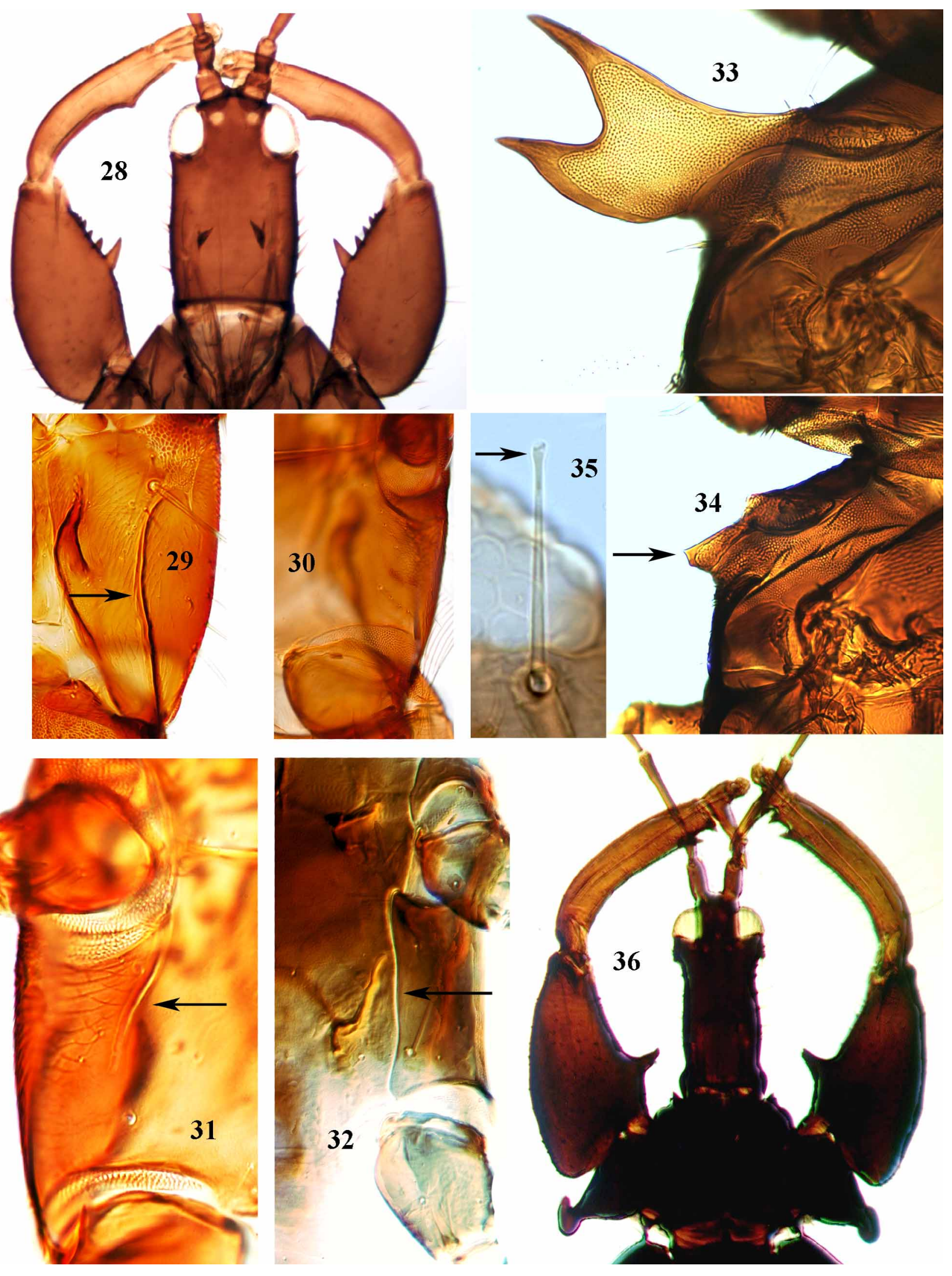

FIGURES 28-36. Idolothripinae species, structural details. (28) Female fore legs, Machatothrips lentus. Metathorax, 29-32: (29) anapleural suture deep and complete, Elaphrothrips (30) sternopleural suture absent, Elaphrothrips, (31) sternopleural suture well-developed, Nesothrips sp., (32) sternopleural suture well-developed and complete, Compsothrips sp.. Male mesothoracic spiracular process, Dinothrips spp., 33-34: (33) forked, (34) plate-shaped. (35) Capitate setae. (36) Male Macrothrips papuensis. 


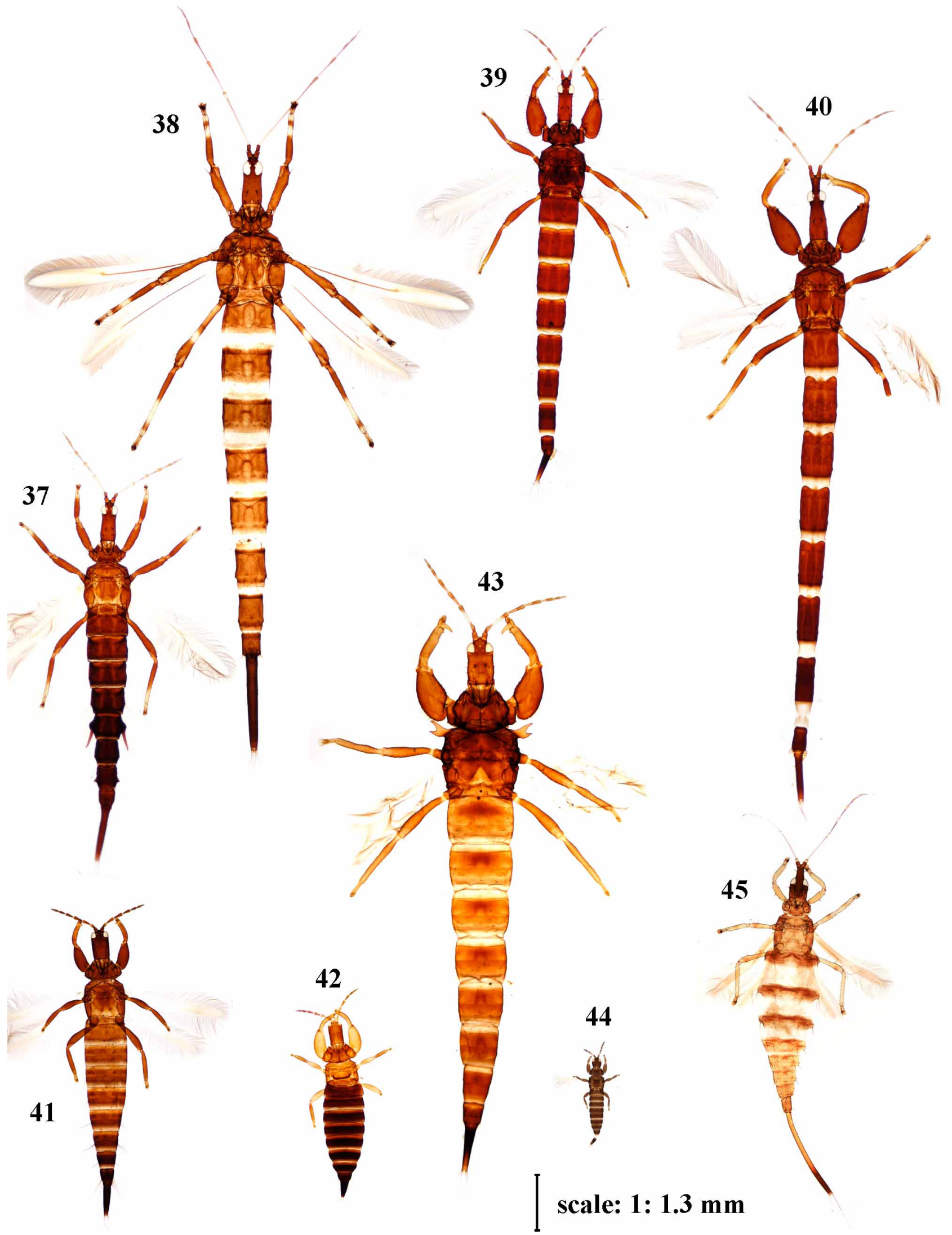

FIGURES 37-45. Idolothripinae species to show relative sizes. (37) Bactrothrips idolomorphus, (38) Meiothrips annulipes, (39) Elaphrothrips bakeri, (40) Mecynothrips simplex, (41) Ethirothrips stenomelas, (42) Ethirothrips tibialis, (43) Dinothrips sp., (44) Gastrothrips acutulus, (45) Holurothrips ornatus. 


\section{Key to genera of idolothripinae from Southeast Asia}

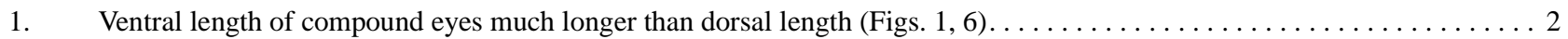

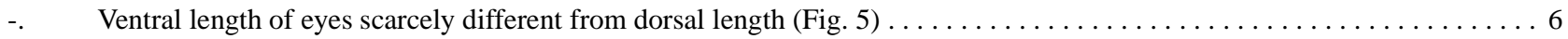

2. Abdominal tube more than 10 times as long as basal width, with prominent lateral setae (Fig. 15) .......... Holurothrips

-. Abdominal tube less than 4 times as long as basal width, without prominent lateral setae (Fig. 14) . . . . . . . . . . .

3. Head strongly prolonged in front of eyes; width of ventral prolongation of eyes comprises at least 2 ommatidia (Figs. 1-2) . .4 Head scarcely prolonged in front of eyes; width of ventral prolongation of eyes comprises only one ommatidium (Fig. 3) . . 5

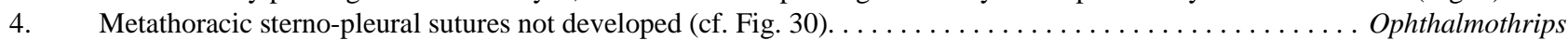

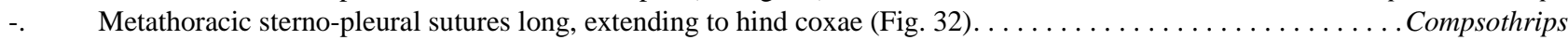

5. Head with a prominent pair of setae between the posterior ocelli $\ldots \ldots \ldots \ldots \ldots \ldots \ldots \ldots \ldots \ldots$ Nesothrips $[$ part $]$

-. Head with one pair of setae posterior to the posterior ocelli, but with no setae between the posterior ocelli $\ldots \ldots \ldots \ldots . .$.

6. Abdominal tergites III-V with at least two pairs of sigmoid (Figs. 9-11) or leaf-like wing-retaining setae (these setae may be

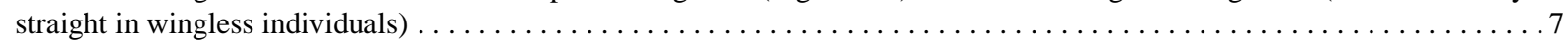
Abdominal tergites III-V with only one pair of sigmoid wing-retaining setae (Fig. 12), or wing retaining setae absent ... . 15

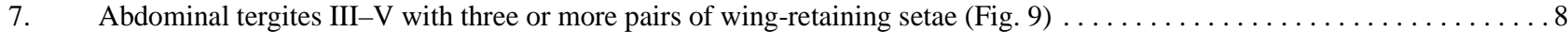

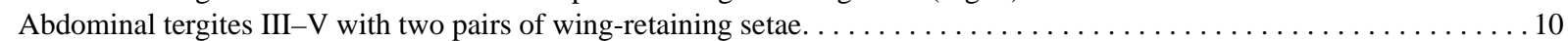
Tergites with three or four pairs of broad, leaf-like wing-retaining setae $\ldots \ldots \ldots \ldots \ldots \ldots \ldots \ldots \ldots$ Paractinothrips

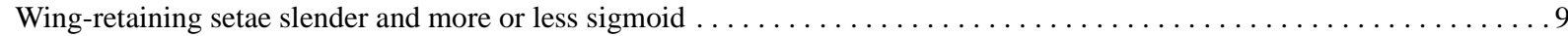

9. Abdominal tergites III-V with 5 pairs of wing-retaining setae; tube more than 20 times as long as basal width

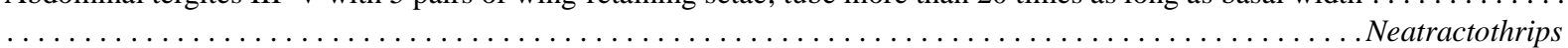
Abdominal tergites III-V with 3 pairs of wing-retaining setae; tube no more than 8 times as long as basal width.

Mecynothrips

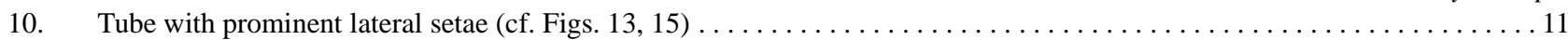

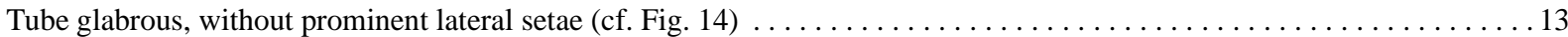

11. Pelta median lobe pointed, lateral wings broadly joined with median lobe; tergites of male without elongate lateral tubercles, but VI-VIII laterally with pairs of stout dagger-like setae each on prominent setal base (Fig. 18) . . . . . . .......Meiothrips Pelta median lobe rounded dome-shaped, lateral wings narrowly joined with median lobe; males with a pair of elongate lateral

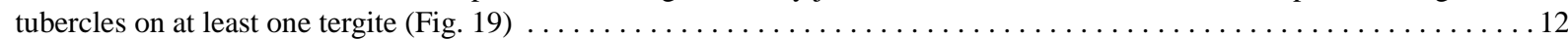

12. Tibiae bicoloured; maxillary stylets V-shaped in head (cf. Fig. 5); male with tergites VI-VIII bearing tubercles laterally, tuber-

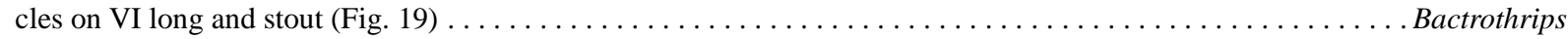
Tibiae uniformly dark; maxillary stylet retracted up to eyes and close together medially (cf. Fig. 7); male with only tergite VI

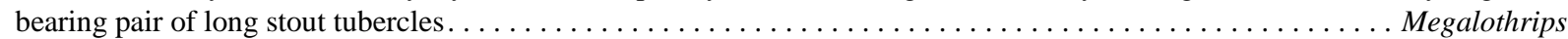

13. Head with complex tuberculate sculpture (Fig. 8); antennal segment II with one or two large dorsal setae; small, dark brown

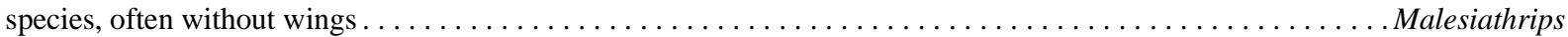
Head smooth, without prominent sculpture (cf. Figs. 4-5); antennal segment II without large dorsal setae; large dark

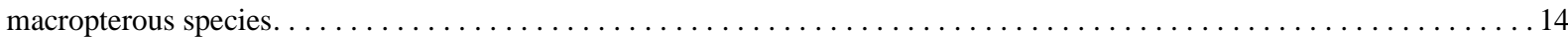

14. Pelta divided into three distinct sclerites (Fig. 17); male usually with distinctive plates laterally on mesothorax developed around spiracular areas (Figs. 33-34); fore femora of males never with sickle-shape seta at external apex ........ Dinothrips Pelta entire, not divided into three parts (except E. jacobsoni); mesothoracic spiracular areas not produced into lateral plates; large males often with sickle-shape seta at external apex of fore femora (Fig. 20) . . . . . . . . . . . Elaphrothrips

15. Antennae 7-segmented, or 8-segmented but with VII-VIII fused with complete or incomplete suture (Fig. 23) . . . . . . . 16 Antennae clearly 8-segmented, VII-VIII distinct from each other, VIII with base either broad (Fig. 22) or constricted (Fig. 21)

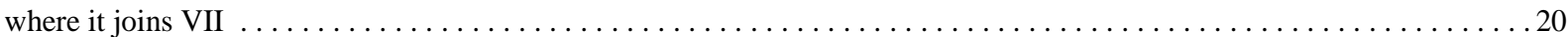

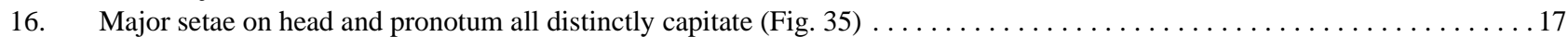

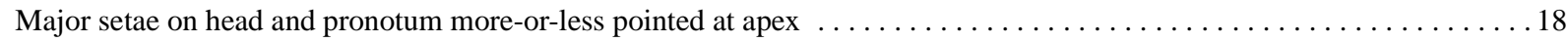

17. Head with 2 pairs of postocular setae; maxillary stylets long and sub-parallel, deeply retracted into head, about one third of head width apart (width cf. Fig. 4); antenna 7-segmented, IV with 2 sensoria (sensoria cf. Fig. 27) . . . .........Allothrips Head with 1 pair of postocular setae; maxillary stylets wide apart and V-shaped in head (cf. Fig. 6); antenna 8-segmented but with VII and VIII fused with incomplete suture, IV with 4 sensoria . . . . . . . . . . . . . . . . . Anallothrips

18. Head longer than wide; maxillary stylets retracted to compound eyes and close together medially (cf. Fig. 7) . . . . Pygothrips Head wider than long; maxillary stylets at least one fifth of head width apart $\ldots \ldots \ldots \ldots \ldots \ldots \ldots \ldots \ldots \ldots$

19. Maxillary stylets widely separated and V-shaped in head; tube commonly swollen with convex margins (Fig. 13); head without an ommatidium-like structure laterally on cheeks $\ldots \ldots \ldots \ldots \ldots \ldots \ldots \ldots \ldots \ldots \ldots \ldots \ldots \ldots$ Acallurothrips Maxillary stylets retracted to compound eyes but about one fifth of head width apart; tube with straight tapering margins (cf. Fig. 14); head with a small ommatidium-like structure (cf. Fig. 4) on posterior third ventrolaterally. . ........Peltariothrips

20. Antennal segment IV with only two sensoria (sensoria cf. Fig. 27); head with one pair of pre-ocellar setae stout and longer than

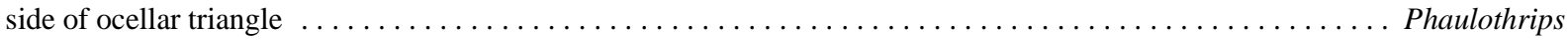
Antennal segment IV with three or more sensoria; post-ocellar setae often large, but pre-ocellar never stout $\ldots \ldots \ldots \ldots 21$

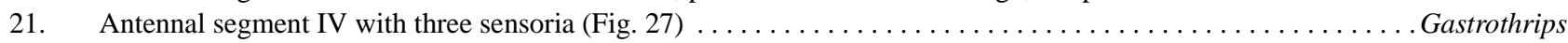

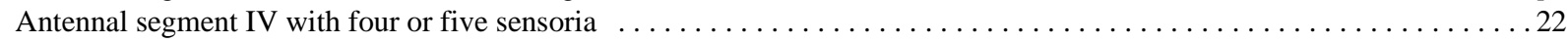

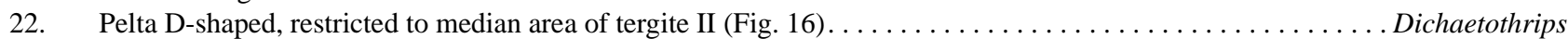

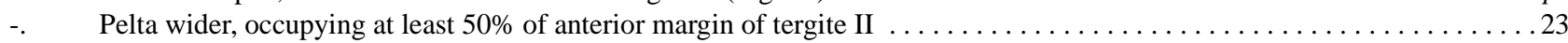


23. Fore tibia with prominent sub-apical tubercle (Fig. 26), rarely absent in female; fore tarsal tooth well-developed in both sexes

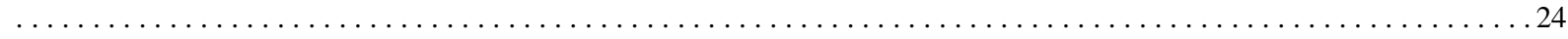

Fore tibia without a sub-apical tubercle but sometimes with a small tubercle at inner apex (Figs. 24-25) . . . . . . . 25

24. Pronotal anterior angles with sharp tubercle in both sexes; male with large recurved tubercle on fore coxae, also large tubercle

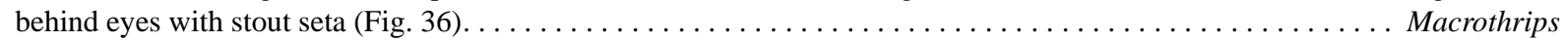

No tubercles on either pronotum, fore coxae or behind eyes in either sex $\ldots \ldots \ldots \ldots \ldots \ldots \ldots \ldots$ Diaphorothrips

25. Head with a pair of ommatidium-like structures ventro-laterally on posterior third of cheeks (ommatidium-like structure cf.

Fig. 4); [Maxillary stylets retracted to eyes and close together medially in head (cf. Fig. 7)] ............Polytrichothrips

Head either without paired ommatidium-like structures on cheeks, or if present then these are in more anterior position. . . 26

26. Head with a pair of ommatidium-like structure at about mid-point of lateral cheek margins [maxillary stylets retracted to eyes

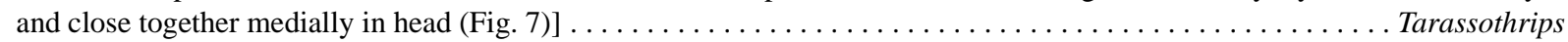
Head either without ommatidium-like structures on cheeks (cf. Fig. 4), or if present then these are close to hind margin of com-

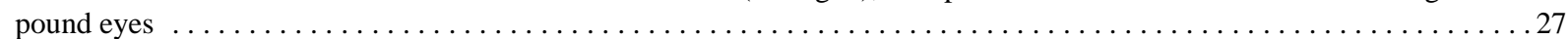

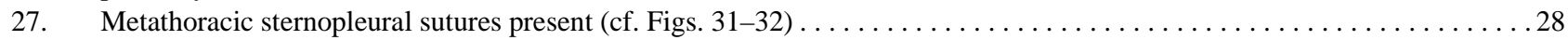

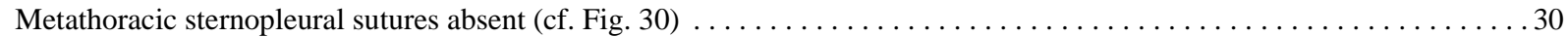

28. Tube heavy and lateral margins convex (cf. Fig. 13), sometimes bearing one or more lateral setal bases. . Neosmerinthothrips

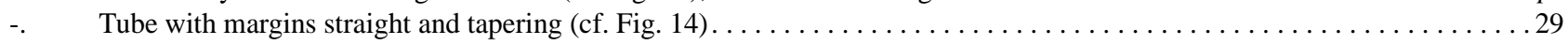

29. Maxillary stylets wide apart, usually V-shaped within head; post-ocellar setae usually arise between the posterior ocelli .....

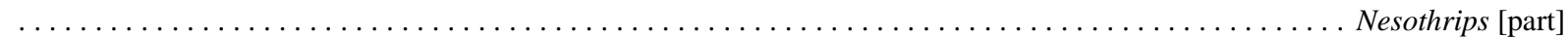
Maxillary stylets no more than one third of head width apart; post-ocellar setae arise behind the posterior ocelli . .........

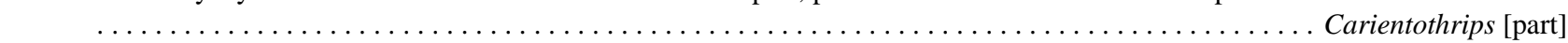

30. Head with a pair of ommatidium-like structures on lateral cheek margins just behind compound eyes (Fig. 4).... Celidothrips

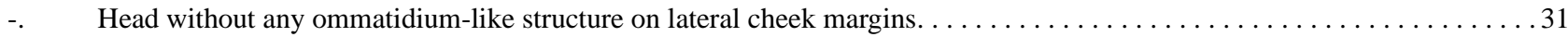

31. Maxillary stylets deeply retracted into head up to level of compound eyes, close together medially (cf. Fig. 7) .Aesthesiothrips

-. Maxillary stylets retracted into head, degree of retraction varies, either widely V-shaped or sub-parallel, but not close together

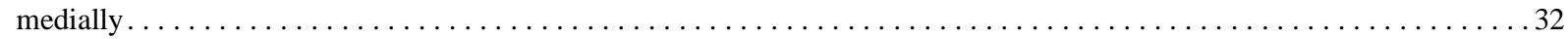

32. Maxillary stylets V-shaped; preocellar setae elongate, length is at least two times the diameter of the ocellus; fore tarsal tooth present in both sexes; female (rarely male) with row of tubercles on inner margin of fore femora (Fig. 28) [if the anterior angles of pronotum have several short stout setae, then female fore femora lack row of tubercles but have the inner margin rugose,

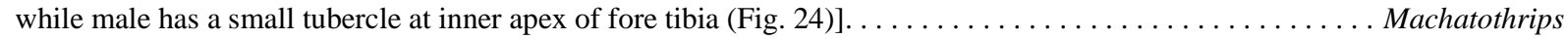
Maxillary stylets V-shaped or sub-parellel; preocellar setae not elongate, length is about the diameter of ocellus or less; fore tarsal tooth present in both sexes but sometimes absent in female; female without row of tubercles on inner margin of fore femora [both sexes sometimes with small tubercle at inner apex of fore tibia (Fig. 25)] ................ Ethirothrips

\section{Tribe Pygothripini}

Members of this tribe have only one pair of sigmoid wing-retaining setae on each abdominal tergite (with two exceptions from Australia). The tube (tenth abdominal segment) is never greatly elongate, usually not more than three times the length of the ninth tergite, and the margins of the tube do not bear prominent lateral setae (with two exceptions, from New Zealand and Fiji). The metathoracic sternopleural sutures are commonly present, although absent in the subtribe Macrothripina, and the metathoracic anapleural sutures are always complete. Six subtribes are recognised in the Pygothripini, and each of these is represented in Southeast Asia.

\section{Subtribe Pygothripina}

These species tend to have long maxillary stylets that are close together medially in the head, and there are usually only two sensoria on both antennal segments III and IV. The subtribe includes ten genera worldwide, but these are mostly from New Zealand and Australia with only two recorded from Southeast Asia.

\section{Phaulothrips}

Fourteen species are described in this genus, of which ten are from Australia, with one each from Samoa and Japan, together with P. orientalis Okajima from Bali and P. melanosomus Okajima from Sulawesi. Species of Phaulothrips have long curved metathoracic sternopleural sutures that arise close to the mesothoracic border. The preocellar region of the head is usually almost vertical, and bears a pair of prominent setae that often arise from slight tubercles. The head is at least slightly elevated in the mid line, and the antennal segments III-IV bear two sensoria. 


\section{Pygothrips}

There are 17 species placed in this genus, from various countries around the world, and although three of these are from Japan and another three from Australia, only one species is recorded from Southeast Asia, P. flavomaculatus Okajima from Obi Island and Indonesia.

\section{Subtribe Allothripina}

Species of the five genera placed in this subtribe are commonly small and wingless, and have the terminal sensorium on the maxillary palps considerably enlarged. This group is found in many parts of the world, but only two genera are recorded from Southeast Asia.

\section{Allothrips}

A total of 24 species-group names are listed in this genus, from many parts of the world, but many of these are sometimes considered as subspecies of two widespread species. Five species are described from Asia, A. bicolor Ananthakrishnan from India, A. discolor Chen and A. taiwanus Okajima from Taiwan, and A. expansus Okajima \& Urushihara and A. magnus Okajima \& Urushihara from Thailand.

\section{Anallothrips}

This genus includes a single species, A. vietotubus Okajima \& Urushihara, known only from Singapore. The species has seven-segmented antennae, where VII and VIII are fused with an incomplete suture.

\section{Subtribe Compsothripina}

Species of the five genera placed in this subtribe are usually found at the base of grasses, and occur in many parts of the world. They usually have three sensoria on the fourth antennal segment, the eyes are commonly prolonged on the ventral surface of the head, and most individuals are wingless. Only one genus is recorded from Southeast Asia.

\section{Compsothrips}

The 27 species listed in this genus are wingless ant-mimics, living at ground level in many warmer parts of the world. The ant-like appearance is often enhanced by the slight elevation of the metanotum, and the constriction of the anterior abdominal segments, and particularly by the running behaviour when alive. Possibly in association with the wingless condition, there is considerable variation between local populations, and the significance of some species as valid entities remains unclear. C. furvus Reyes is described from the Philippines, but is closely similar in structure and colour to $C$. reuteri Trybom from South Africa. The record of $C$. congoensis Hood from India (Ananthakrishnan \& Sen, 1980) possibly refers to the same species, and similar specimens have been studied from Chiang Mai, Thailand. In contrast, C. ramamurthii Ananthakrishnan from India has the body more extensively yellow. No member of the genus is recorded from Japan.

\section{Subtribe Gastrothripina}

This group includes only one genus. The species have only three sensoria on the fourth antennal segment, and welldeveloped metathoracic sternopleural sutures. 


\section{Gastrothrips}

This genus is found worldwide throughout the tropics. It currently includes 37 described species, and these live on dead twigs and branches. The Neotropical species usually have the tube constricted apically, whereas the Palaeotropical species usually have the tube with straight, tapering sides. Structural variation between samples is particularly difficult to interpret among these Palaeotropical species. For example, G. acutulus Okajima, recorded from southern Japan (Ryukyu Islands), Taiwan, Philippines, Sabah, Thailand and Peninsular Malaysia (Okajima, 2006), is possibly the same species as G. falcatus Ananthakrishnan from India. The large males of this species have a remarkable prolongation posteromedially on the metanotum. Also recorded from Peninsular Malaysia is G. acuticornis Hood, a species that was described from the West Indies but is known from northern Australia and New Caledonia. The only other species recorded from Southeast Asia is G. curvidens Karny from Java.

\section{Subtribe Diceratothripina}

A total of 11 genera, from tropical countries across the world, are placed in this group. The species usually have well-developed metathoracic sternopleural sutures, antennal segment IV bears four sensoria, and the maxillary stylets are wide apart from each other, often V-shaped in position.

\section{Acallurothrips}

There are currently 22 species listed in this genus, most of which have antennal segments VII and VIII broadly joined. Many of these species are from South America or South Africa, but six species are known only from Japan and one from Fiji. In Southeast Asia, only two species are recorded, A. metulicauda Karny from Java, and A. tubullatus Wang \& Tong from southern China, although unidentified species are known from northern Australia living on dead branches.

\section{Carientothrips}

Most of the 18 species listed in this genus are from Australia or Pacific island territories, with one species, C. grayi Mound, from New Guinea. These thrips live on dead branches, but with several species associated with fungi at the base of grasses. This genus is closely related to Nesothrips Kirkaldy (Mound \& Palmer, 1983), with similar morpho-character problems in taxonomy-the compound eyes of some species are not prolonged ventrally.

\section{Neosmerinthothrips}

The 21 species listed in this genus are closely similar to those placed in Acallurothrips, but with the terminal two segments of the antennae more distinctly separated. The generic classification of all these species needs further study. N. xylebori Priesner from Java is the only described species recorded from Southeast Asia, but there are undescribed species known from northern Australia.

\section{Nesothrips}

This genus of 28 species is particularly well represented in Australia and the Pacific islands. One species, $N$. yasumatsui Okajima, is described from Thailand, but three species have been distributed through human trading widely around the world, including various Southeast Asian countries. These are, $N$. lativentris Karny, apparently associated with dead fronds and fruits of coconut palm trees, N. propinquus Bagnall, associated with dead grasses and hay, and N. brevicollis Bagnall, associated with dead twigs. $N$. propinquus Bagnall often has the compound 
eyes prolonged ventrally, but this character is variable and eyes may be scarcely prolonged at all (Mound, 1974). Members of this genus usually have a pair of strong setae arising between the posterior ocelli.

\section{Subtribe Macrothripina}

All but one of the 13 genera in this subtribe are from the Old World tropics, mostly from the Asian and Pacific regions. In contrast to the other members of the Pygothripini, none of the species has the metathoracic sternopleural sutures developed.

\section{Aesthesiothrips}

The only species in this genus, A. jatrophae Ananthakrishnan, is known from India and Malaysia. It has very long maxillary stylets that are deeply retracted into the head and close together medially, and in both sexes each fore tibia bears a small apical tubercle.

\section{Celidothrips}

Four species are listed in this genus, all of which have an ommatidium-like structure on the cheeks just behind the compound eyes. Two of the species are from northern Australia, and one is from Guadalcanal. C. adiaphorus Karny was described from Java, and specimens have been studied from Peninsular Malaysia that probably represent this species.

\section{Diaphorothrips}

Five species are listed in this genus, all of which are associated with dead branches. One species is from India and Sri Lanka, and another from Fiji. In Southeast Asia, D. pugnator Okajima is known only from Sabah, D. clavipes Priesner is known only from Peninsular Malaysia, Singapore and the nearby Riau Islands, while D. hamipes Karny, described from Java, occurs in Sumatra and Peninsular Malaysia.

\section{Dichaetothrips}

This genus includes four species. The original species, D. brevicollis, remains known from a single female taken in Guyana, South America, and no further specimens have ever been recorded from anywhere in the Neotropics (Mound \& Marullo, 1996). The other three species are all from Southeast Asia. Of these, D. senohi Okajima is based on a single male from Java, D. okajimai Mound \& Palmer is known only from Singapore and Peninsular Malaysia, while D. secutor Mound \& Palmer is recorded from Thailand, Laos, Peninsular Malaysia and the Ryukyu Islands of southern Japan.

\section{Ethirothrips}

The total of 37 species currently listed in this genus seems likely to be a considerable under estimate. Not only is Ethirothrips, with seven generic synonyms, interpreted as a complex genus encompassing a considerable range of structural diversity, but species recognition within this complex is particularly difficult due to lack of good series from which to interpret polymorphisms. All the species are associated with dead branches, but many are known from few specimens. The genus is widespread from India to Taiwan and into the Pacific, with many described, and undescribed, species in Australia. Two identified species are known from Peninsular Malaysia, E. stenomelas 
Walker is widely dispersed around the tropics, and E. tibialis Okajima, described from southern Japan (Ryukyu Islands), is known also from Sabah and Thailand (Okajima, 2006).

\section{Machatothrips}

A key to the 14 species recognised in this genus was provided by Palmer \& Mound (1978), these species being distributed from West Africa through Asia to New Guinea. However, recently collected material suggests that the validity of some of the species recognised by these authors is uncertain, because the lengths of some of the major setae appear to be far more variable than was previously accepted, and males in particular cannot be identified with any certainty. Species in this genus are unusual amongst Idolothripinae in that it is females, not males, that have the fore femora armed, although the fore tarsal tooth of males is larger and stouter than that of females. The behavioural significance of this remains unknown. Moreover, in two species described from Malaysia, M. decorus Palmer \& Mound and M. lentus Palmer \& Mound, males as well as females have armed fore femora. In Peninsular Malaysia three species have been collected commonly from dead branches, M. antennatus Bagnall, M. biuncinatus Bagnall, and M. lentus Palmer \& Mound, whereas M. heveae Karny has been taken infrequently. Also recorded from Asia are two species from Taiwan, three from India, and one from New Guinea.

\section{Macrothrips}

This genus comprises a single variable species, M. papuensis Bagnall, that is known only from New Guinea. Large males, with a body length of almost $15 \mathrm{~mm}$, are probably the largest of all Thysanoptera, with a forwardly recurved tubercle on the upper surface of each fore coxa, and a short postocular seta arising from a tubercle.

\section{Peltariothrips}

Only one species is recognised in the genus, $P$. insolitus Mound \& Palmer. Described from Singapore and the Philippines, this species has only seven antennal segments, the terminal two segments being fused, and the head bears a pair of ommatidium-like structures ventro-laterally on the posterior third of the cheeks.

\section{Polytrichothrips}

Two species are described in this genus, P. laticeps Bagnall from Sarawak, and P. geoffri Mound from northern Australia, although specimens of a further species have been studied from New Caledonia. These species have the maxillary stylets elongate, retracted to the level of the compound eyes and close together medially, and there is a pair of ommatidium-like structures ventro-laterally on the posterior fifth of the cheeks.

\section{Tarassothrips}

Only two species are recognised in this genus, T. akritus Palmer \& Mound from Peninsular Malaysia and Singapore, and T. grandis Okajima from Philippines. These have the maxillary stylets elongate, retracted to the level of the compound eyes and close together medially, and there is a pair of ommatidium-like structures ventro-laterally on the anterior third of the cheeks.

\section{Tribe Idolothripini}

Species placed in this tribe do not have metathoracic sternopleural sutures, the tergites almost always have two or more pairs of wing-retaining setae, and the tube bears long lateral setae. The tribe is represented throughout the tropics, and three subtribes are recognised. 


\section{Subtribe Idolothripina}

This group comprises 10 genera. Most of the described species are from the Old World tropics, but the group has also radiated slightly into the Holarctic region, possibly more than once. The males commonly have elongate tubercles (drepanae) laterally on one or more tergites. These males lack a fore tarsal tooth, and this suggests that in these species male/male competition involves the use of the abdomen as a weapon rather than the fore legs. The generic classification is less than satisfactory, with genera distinguished on the form of the abdominal turbercles and the length of the maxillary stylets.

\section{Bactrothrips}

There are 46 species currently listed in the genus Bactrothrips, mostly from Africa (Mound \& Palmer, 1983), and these are usually found on dead branches with dry leaves. Most of the species are distinguished from each other by the number and size of lateral tubercles on the abdomen of males. However, males vary greatly in size, and the species taxonomy within the genus is thus probably not secure. Of the few species known from the Oriental region, only the seven species from Japan are well characterised (Okajima, 2006). B. idolomorphus Karny is widespread across Asia from Sri Lanka to Malaysia, B. guineaensis Moulton was described from New Guinea, B. luteus Ananthakrishnan from India, and B. nativus Girault from Australia.

\section{Megalothrips}

There are seven species listed in this genus, and these seem to occur both in leaf litter and on dead branches. Five of the species are Holarctic (two European, three North American) and two are Asian. M. andrei Mound \& Palmer is known only from a few specimens taken near Kuala Lumpur, but $M$. curvidens Okajima has been found widely in southern Japan from Honshu to the Ryukyu Islands. Okajima (2006) indicated that these two may represent local variants of a single species.

\section{Meiothrips}

The five species placed in this genus are all from the Oriental region, and have long and slender bodies with elongate antennae and tube. These species are usually found on dead branches with dry leaves, and there is a curious diversity in some character states within the genus. M. annulipes Bagnall is known from Borneo and Sumatra, and has been taken commonly in Peninsular Malaysia. This species differs from the others in having no duplicated cilia on the fore wings. M. menoni Ananthakrishnan is widespread from India to Thailand, and is also recorded from Peninsular Malaysia. However, M. baishanzuensis Duan \& Li from southern China is possibly the same species as M. nepalensis Kudo \& Ananthakrishnan from Nepal and Thailand. M. kurosawai Okajima from Sabah is known from a single female that differs from the other four species in having the head prolonged in front of the eyes, and the eyes prolonged ventrally; in these characters this species resembles the members of the genus Holurothrips.

\section{Subtribe Elaphrothripina}

Males in this group do not have lateral tubercles on the abdomen, and the tube is never particularly long. However, they commonly have the fore tarsi with a well-developed tooth and the fore femora enlarged, and this presumably reflects the style of male/male competition that occurs in these species. The maxillary stylets are widely spaced within the head, and paired prosternal basantra are present. A total of 10 genera are recognised, of which five are known from Southeast Asia. 


\section{Dinothrips}

There are six species listed in this genus, all from Southeast Asia between Sri Lanka, Philippines and southern China. However, recent material collected in Malaysia indicates that the species taxonomy is not secure. Palmer \& Mound (1978) provided a key to distinguish the five species known at that time, but the character states given by these authors for D. spinosus Schmutz and D. sumatrensis Bagnall do not distinguish all available specimens. Moreover, specimens referable to these two forms have been taken together at several sites, both in Malaysia and other Asian territories. An alternative explanation, that these specimens represent a single variable species, requires further testing, preferably with molecular data. Only one of the six species, D. monodon Karny from Philippines, seems to be distinctive morphologically. $D$. hainanensis Zhang from southern China, together with $D$. juglandis Moulton and $D$. longicauda Ananthakrishnan from India, are possibly variants of $D$. sumatrensis. The process associated with the mesothoracic spiracle in males of this genus is highly variable, from large and bifurcate to almost non-existent.

\section{Elaphrothrips}

Currently, there are 140 species listed in this genus, with a further 39 species placed into synonymy. This high rate of synonymy reflects the considerable variation in body size among males, including allometry of several structures, together with the considerable differences in structure between the sexes. Moreover, examination of samples collected recently in Peninsular Malaysia indicates the possibility that one or two Asian species exist as clines between India and Indonesia. Species taxonomy within the genus remains unreliable, and requires further testing with molecular data, in collaboration with behavioural information on breeding and male/male competition, and ecological studies on resource partitioning in the habitat of hanging dead leaves where these insects are sometimes abundant. It seems likely that more synonymy remains to be detected (Mound \& Palmer, 1983). The following 18 species are recorded from various Asian countries: E. amoenus Priesner (Vietnam); E. athletes Karny (Java); E. bakeri Karny (Phlippines, Java, Sumatra); E. coreanus Woo (Korea); E. curvipes Priesner (Sumatra, India); E. denticollis Bagnall (Indonesia, India); E. fulmeki Priesner (Sumatra); E. greeni Bagnall (Sri Lanka, India); E. insignis Ananthakrishnan (India); E. insulamris Priesner (Java); E. jacobsoni Priesner (Sumatra); E. malayensis Bagnall (Indonesia, Sri Lanka); E. notabilis Ananthakrishnan (India); E. philippinensis Okajima (Philippines); E. procer Schmutz (Sri Lanka, India); E. sensitivus Priesner (Sumatra); E. spiniceps Bagnall (India, Java); E. sulawesiensis Okajima (Sulawesi).

\section{Malesiathrips}

Four species are listed in this genus, and of these one from Guam and another from the Solomon Islands are readily distinguished (Palmer \& Mound, 1978). In contrast, M. australis Mound, based on apterae from northern Australia, is closely similar to M. malayensis Palmer \& Mound, based on macropterae from Peninsular Malaysia and Java. Both of these species live on the dead spiny branches of Calamus species, the climbing rattan palms.

\section{Mecynothrips}

This genus of 14 large-bodied species effectively replaces Elaphrothrips East of Wallace's Line. Because of size variation and allometry among males there are also 14 species-group names placed into synonymy. M. simplex Bagnall was described from Philippines, but is widespread from there to Sri Lanka and India, including Malaysia, Java, and Borneo. In contrast, most of the other 13 species are known only from single samples and, despite the key to species provided by Palmer \& Mound (1978), a full understanding of the variation among these species has yet to be established. It is likely that further study will indicate more synonymy. 


\section{Ophthalmothrips}

Although 11 species are listed in this genus, species recognition remains unsatisfactory because some are based on winged but others on wingless individuals. They apparently live at the base of grasses. In Southeast Asia, two species are described from India, two from Japan, one from Taiwan, and one from southern China (Sichuan).

\section{Subtribe Hystricothripina}

This group includes 13 genera, of which eight are from the Neotropics, one from Florida and Mexico, one from Africa, and three from Southeast Asia. The species all have prominent setae laterally on the tube, the prosternal basantra are absent or at least weak. Only one pair of tergal wing retaining setae is present in most species, but the Asian species have multiple such setae ranging from three to five pairs.

\section{Holurothrips}

The three species included in this genus comprise one from northern Australia, one from southern Japan and southern China, and H. ornatus Bagnall from Indonesia and Peninsular Malaysia. These species all seem to be associated with rather damp leaf-litter, and are remarkable for the long projection of the head in front of the eyes, with the eyes prolonged ventrally. The fore wings in these species have many duplicated cilia, in contrast to species in the following two genera.

\section{Neatractothrips}

Only one species is known in this genus, $N$. macrurus Okajima from the Ryuku Islands and the Philippines. The tube has sparse lateral setae and is exceptionally long, almost four times as long as the head, the fore wings lack duplicated cilia, and the tergites bear five pairs of wing retaining setae.

\section{Paractinothrips}

The only species in this genus, P. peratus Mound \& Palmer, is known from Peninsular Malaysia and the Philippines. The tube is about three times as long as the head, the tergites bear three pairs of broadly flattened, leafshaped wing retaining setae, and the fore wings lack duplicated cilia.

\section{Acknowledgements}

This research has received funding from research grants 06-01-02-SF-0540 and STGL-002-2008. A three months study visit (by Eow, L. X.) to the Australian National Insect Collection at CSIRO Ecosystem Sciences was supported by GUP-ASPL-07-04-048 and also the Global Student Mobility Partnerships Program (Outbound), UKM.

\section{References}

Ananthakrishnan, T.N. \& Sen, S. (1980) Taxonomy of Indian Thysanoptera. Zoological Survey of India (Handbook Series), 1, $1-234$.

Crespi, B.J. (1989) Sexual selection and assortative mating in subdivided populations of the thrips Elaphrothrips tuberculatus (Insecta: Thysanoptera). Ethology, 3, 265-278.

Hoddle, M.S., Mound, L.A. \& Paris, D. (2008) Thrips of California. CD-ROM published by CBIT, Brisbane. http://www.lucidcentral.org/keys/v3/thrips_of_california/Thrips_of_California.html 
Kranz, B.D., Shibata, T., Tsuchida, K. \& Okajima, S. (2002) Reproductive mode and split sex ratios in the facultatively ovoviviparous thrips, Bactrothrips brevitubus. Evolutionary Ecology Research, 2002, 4, 1075-1092.

Moritz, G., Mound, L.A., Morris, D.C. \& Goldarazena, A. (2004) Pest thrips of the world-visual and molecular identification of pest thrips. CD-ROM published by CBIT, Brisbane. http://www.cbit.uq.edu.au/software/pestthrips/default.htm

Morse, J.G. \& Hoddle, M.S. (2006) Invasion biology of thrips. Annual Review of Entomology, 51, 67-89.

Mound, L.A. (1974) The Nesothrips complex of spore-feeding Thysanoptera (Phlaeothripidae: Idolothripinae). Bulletin of the British Museum (Natural History) Entomology Series, 31, 107-188.

Mound, L.A. (2005) Thysanoptera: Diversity and Interactions. Annual Review of Entomology, 50, 247-269.

Mound, L.A. (2011) Thysanoptera (Thrips) of the World-a checklist. http://www.ces.csiro.au/thysanoptera/worldthrips.html [accessed 30.v.2011]

Mound, L.A. \& Azidah, A.A. (2009) Species of the genus Thrips (Thysanoptera) from Peninsular Malaysia, with a checklist of recorded Thripidae. Zootaxa, 2023, 55-68.

Mound, L.A. \& Kibby, G. (1998) Thysanoptera: An Identification Guide, 2nd edition. CAB International, Wallingford. 70pp.

Mound, L.A. \& Marullo, R. (1996) The Thrips of Central and South America: An Introduction. Memoirs on Entomology, International, 6, 1-488.

Mound, L.A. \& Ng, Y.F. (2009) An illustrated key to the genera of Thripinae (Thysanoptera) from South East Asia. Zootaxa, $2265,27-47$.

Mound, L.A. \& Palmer, J.M. (1983) The generic and tribal classification of spore-feeding Thysanoptera (Phlaeothripidae: Idolothripinae). Bulletin of the British Museum (Natural History). Entomology, 46, 1-174.

Mound, L.A., Paris, D. \& Fisher, N. (2011) World Thysanoptera - an information resource. http://anic.ento.csiro.au/thrips/ index.html [accessed 30.v.2011]

Ng, Y.F., Eow, L.X. \& Mound, L.A. (2010) A new species of genus Thrips (Thysanoptera, Thripinae) from flowers in Peninsular Malaysia. Zootaxa, 2638, 65-68.

Nonaka, T. \& Jangvitaya, P. (1994) Bamboo-inhabiting thrips of the family Thripidae (Thysanoptera) from Southeast Asia I. Japanese Journal of Entomology, 62, 41-53.

Okajima, S. (1993) The genus Alerothrips (Thysanoptera, Phlaeothripidae), with descriptions of two new species from Thailand. Japanese Journal of Entomology, 65, 773-783.

Okajima, S. (1998) The genus Andrethrips (Thysanoptera: Phlaeothripidae), with description of a new species. Entomological Science, 1, 71-76.

Okajima, S. (2002) Watanabeothrips yasuakii (Thysanoptera, Thripidae), a new genus and species from Thailand with remarkable sexual dimorphism in setal shape. Special Bulletin of the Japanese Society of Coleopterology, 5, 111-118.

Okajima, S. (2006) The Suborder Tubulifera (Thysanoptera). The Insects of Japan, 2, 1-720. The Entomological Society of Japan, Touka Shobo Co. Ltd., Fukuoka.

Palmer, J.M. \& Mound, L.A. (1978) Nine genera of fungus-feeding Phlaeothripidae (Thysanoptera) from the Oriental Region. Bulletin of the British Museum (Natural History). Entomology, 37, 153-215.

Reyes, C.P. (1994) Thysanoptera (Hexapoda) of the Philippine Islands. Raffles Bulletin of Zoology, 42, $107-507$.

Shibata, T., Kranz, B.D. \& Tsuchida, K. (2007) Rearing method for the sporophagous thrips Bactrothrips brevitubus (Thysanoptera: Phlaeothripidae: Idolothripinae). Entomological Science, 10, 129-133.

Tree, D.J., Mound, L.A. \& Walter, G.H. (2010) Fungal spore-feeding by adult and larval Mecynothrips hardyi (Priesner) (Thysanoptera: Phlaeothripidae: Idolothripinae). Journal of Natural History, 44, 307-316.

zur Strassen, R. (1994) Some reflections on the composition of the thrips fauna (Insecta: Thysanoptera) of Bali (Indonesia) along the biogeographical Bali-Lombok line. Courier Forschungsinstitut Senckenbergiana, 178, 33-48. 